\title{
Sexuality of women with diabetes
}

\author{
Rosemary J Basson MB BS MRCP ${ }^{1}$, Bianca M Rucker PhD², Philip G Laird PhD ${ }^{3}$, Robert Conry PhD ${ }^{4}$ *
}

RJ Basson, BM Rucker, PG Laird, R Conry. Sexuality of women with diabetes. J Sex Reprod Med 2001;1(1):11-20.

OBJECTIVES: To gain a more detailed understanding, from a biopsychosocial perspective, of the sexuality of women living with diabetes.

DESIGN: Anonymous questionnaire study.

METHOD: Thirty-six women with type 1 diabetes, 27 women with type 2 diabetes and 67 women without diabetes completed anonymous, detailed surveys about their sexual desire, sexual satisfaction, sexual self-view and sexual function. Various features of diabetes that have potential sexual relevance were also addressed.

RESULTS: Women with diabetes recognized that the following factors are associated with their disease and affect their sexuality: diabetes-associated fatigue, fear of becoming dependent on a sexual partner and an impairment of body image that is associated with diabetes. Other potential diabetes-associated concerns, including issues of fertility, birth control, difficulty finding an accepting partner and the perception of being an 'ill' woman, were not found to be relevant to sexual desire or sexual function. Women with diabetes were found to be similar to women without diabetes in terms of sexual desire, sexual responses and sexual function. Dyspareunia, which was disconcertingly common in all groups, is discussed.

CONCLUSIONS: Despite the likelihood of diabetesassociated impairment of genital sexual physiology in women, any effect on women's sexual function appears to be limited. Sexual satisfaction, however, may be affected by factors to do with living with diabetes.

Key Words: Diabetes; Sexual desire; Sexual response; Women

\section{La sexualité chez les femmes diabétiques}

OBJECTIF : Mieux comprendre, du point de vue biopsychosocial, la sexualité chez les femmes diabétiques.

PLAN D'ÉTUDE : Questionnaire anonyme.

MÉTHODE : Trente-six femmes atteintes de diabète de type I, 27 femmes, de diabète de type II et 67 femmes non diabétiques ont rempli, de façon anonyme, un questionnaire détaillé sur leurs pulsions sexuelles, leur satisfaction sexuelle, le fonctionnement sexuel et leur point de vue personnel sur la sexualité. Nous nous sommes également intéressés à différents aspects du diabète, susceptibles d'avoir une incidence sur la vie sexuelle.

RÉSULTATS : Les femmes diabétiques ont déclaré que les facteurs suivants, associés à leur maladie, influaient sur leur sexualité : la fatigue associée au diabète, la crainte de devenir dépendante d'un partenaire sexuel et une altération de l'image corporelle associée au diabète. Par contre, nous avons constaté que d'autres préoccupations liées au diabète, par exemple les problèmes d'infertilité, la limitation des naissances, la difficulté de trouver un partenaire qui accepte la maladie et la perception d'être une femme «malade » n'avaient pas d'incidence sur les pulsions ou le fonctionnement sexuels. Les femmes diabétiques n'étaient pas différentes des femmes non diabétiques sur le plan des pulsions sexuelles, des réactions sexuelles et du fonctionnement sexuel. Il a également été question de dyspareunie, trouble étonnamment courant dans tous les groupes.

CONCLUSION : Malgré les risques de perturbation de la physiologie sexuelle génitale, liée au diabète, il semble bien que la maladie ait des répercussions limitées sur le fonctionnement sexuel. Toutefois, certains facteurs associés au fait de vivre avec le diabète se sont avérés susceptibles d'avoir une incidence sur la satisfaction sexuelle.

\footnotetext{
${ }^{1}$ Departments of Psychiatry, and Obstetrics and Gynecology, University of British Columbia and Centre for Sexuality, Gender Identity and Reproductive Health, Vancouver Hospital, Vancouver; ${ }^{2}$ Sexual and Marital Therapy, Private Practice, Vancouver; ${ }^{3}$ Department of Psychology, Trinity Western University, Langley; ${ }^{4}$ Department of Counselling Psychology, University of British Columbia, Vancouver, British Columbia 
A review of the literature suggests that there is no consistent change in the sexuality or sexual function of women with either type 1 or type 2 diabetes. The tendency to examine a woman's sexual desire and response with reference to the male model of sexuality and function is common to all studies. However, men and women have very different 'sexual programming', and their most common sexual dysfunctions or complaints are not simply physiological equivalents (1).

Generally, men have higher levels of spontaneous sexual desire than women (see review of supporting data by Baumeister et al [2]), most likely based in part on genetic factors and 10-fold higher testosterone levels compared with women. Men's sexual drive contributes much to the enjoyment of the sexual experience with a partner or alone. For both types of activity, but especially during sexual activity with a partner, a firm and not just tumescent penis is necessary. Thus, the most common male sexual dysfunction is erectile dysfunction. Even nonerectile sexual problems (eg, low desire, premature ejaculation) are often presented in terms of erectile failure. The inherent biological vulnerability of the erectile mechanism compounds the requirement of a firm penis. Vascular health, especially the availability of endothelial nitric oxide (NO), which is an integral component of the expansion of corporal tissue, commonly decreases with diabetes (3). Given the perceived mandatory requirement of a firm penis, any physically based deficiency quickly becomes compounded by interpersonal and intrapersonal factors (4).

In contrast to men's sexual desire, women's desire is often perceived as being more responsive than spontaneous, as is reflected in the new American Foundation of Urological Disease consensus definition of female hypoactive sexual desire disorder (5). It may be triggered by a multiplicity of factors in addition to conventional sexual stimuli. Women's desire may be expressed more as wanting physical closeness, intimacy, and to share love and affection rather than wanting the pure physical pleasure of sexual acts $(1,6)$. The need for physical pleasure is commonly accessed once the sexual experience has begun (7). Research by Regan and Berscheid (6) shows that the goals of sexual desire are distinctly different for men and women.

Most women are relatively unaware of the state of vasocongestion of the genitalia. They mainly refer to subjective arousal when speaking of sexual arousal (8). Their appraisal of sexual stimuli and their context, rather than the conscious appraisal of genital vasocongestion, determines their subjective arousal (9). Women speak of problems that reflect a lack of engorgement of the clitoris, the vaginal wall, vestibular bulbar tissue or the erectile tissue around the uretha rather infrequently. The vast majority of this erectile tissue is hidden from view in women. Partial rather than full engorgement may not interfere with sexual pleasure from stimulation. Neither a woman nor her partner is likely to be aware that the physiological response is only a partial response. Women may complain of insufficient lubrication from vaginal capillaries despite an intact desire for a sexual experience and adequate mental arousal. This situation is usually a reflection of reduced estrogen production postmenopausally (estrogen is needed for the process of lubrication, which is, most likely, predominantly vasointestinal polypeptide-mediated) $(10,11)$. Female (genital) sexual arousal disorder (FSAD) is not the overriding female sexual dysfunction as erectile dysfunction is for men. Nevertheless, Park et al (12) developed an atherosclerotic animal model to mimic the pathophysiology of 'vasculogenic FSAD'. The flaw with this approach is that there is a fundamental difference in women's and men's appraisal of genital congestion. Women with and without FSAD have been studied in a laboratory setting. When an erotic stimulus is presented, within seconds, both groups of women experience an increase in vaginal congestion (as measured by a vaginal pleythysmograph). This finding is true regardless of whether the stimulus is reported as being subjectively arousing and even if the stimulus is perceived as being negative (8).

It appears, therefore, that in perhaps many women, accurate awareness of the state of the genitalia is either lacking or irrelevant to subjective arousal. There is also no requirement for a woman's erectile tissue to be in a critical state of engorgement for her to be 'potent'. Thus, a degree of impairment of erectile and lubrication responses similar to that induced in an animal model may not be clinically relevant in the human female. Clearly, marked vascular insufficiency that precludes vulval congestion would cause direct genital stimulation (a common means by which women move from a sexually neutral state to one of arousal [7]) to be ineffective and, even, painful. Similarly, marked vascular insufficiency that precludes lubrication would be problematic if a woman wished to include intercourse in her sexual experience.

With the background information presented above, the relevance of diabetes-associated vascular and neurological pathology may be addressed. The brain's signal of sexual arousal is transmitted by the autonomic nervous system to the genital erectile tissue in both sexes and to women's submucosal vaginal microvasculature. This neurotransmission to the erectile tissue involves NO (13) and other neurotransmitters, and causes relaxation of the smooth muscle surrounding the minute blood spaces (sinusoids) in the clitoris and in the vestibular bulb. It also facilitates the release of NO from the endothelial cells that line the sinusoids. The neurotransmission to the vascular smooth muscle in the vaginal submucosa, which is most likely vasointestinal polypeptide- and NO-mediated, increases the inflow of blood, thereby increasing intracapillary pressure and the transudation of lubricating fluid. This autonomic neurological conduction is most likely to be inefficient in patients with diabetes. Additionally, there is less NO in the endothelial cells to be released (3). Supply arteries may be prematurely stiffened with atheroma, and with time, relative anoxia causes the loss of smooth muscle, further inhibiting the process of engorgement. Given the differences in the sexual function of men and women mentioned above, the engorgement of erectile tissue is clearly of major importance to a man with 
diabetes but may well be less critical to a woman with diabetes. Similarly, lubrication may still be 'sufficient', even if a decrease in vascular response is documented.

\section{REVIEW OF PREVIOUS STUDIES}

In a 1994 review of the available literature on women's sexuality and diabetes, Thomas and LoPicollo (14) reviewed 16 studies and concluded: "For women the connection between diabetes and sexual function appears to be much less clear than for men, and also appears to contain a larger psychological element". The authors point to the lack of physiological studies, but as has been noted above, the relevance of laboratory-based physiological studies to a woman's sexual experience is unclear given the small correlation that exists between genital and subjective indices of sexual arousal (15). It is necessary to know the effect of any defect in genital physiology on a woman and her partner, rather than simply to identify its presence.

Sexual identity and self-image are important components of sexuality that often affect women's sexual desire, but are rarely addressed. There are no formal sexology studies either of delayed psychosexual maturation in women diagnosed with diabetes at an early age (16), or of the use of insulin manipulation, enemas and laxatives to reduce the weight that is typically gained from insulin (17). Sexual concerns outside the sphere of hypoactive sexual desire or disordered genital reflexes are commonly ignored (18).

Interpersonal issues have only occasionally been examined, and there is little correlation between sexual dysfunction and marital difficulties (19). Schreiner-Engel et al (20) noted that while women with type 1 diabetes were similar in most respects to women in the control group, those with type 2 diabetes did report more unhappiness and discord in their relationships. Unfortunately, the vast majority of studies have only investigated married or cohabiting women (exceptions include Newman and Bertelson [19], and Hulter et al [21]).

Difficulties with birth control, fertility and pregnancy outcome are common in women with diabetes. Whether these factors affect a woman's sexual willingness and ability is unknown.

Low sexual desire that is associated with high blood sugar levels, interference with sexual response from painful neuropathy, recurrent cystitis, vaginitis and pain from vulvar vestibulitis syndrome, which is potentially precipitated by Candida albicans infection $(22,23)$, await detailed study.

The only indication of persistently lowered sexual desire can be found in the study by Schreiner-Engel et al (20) in which women with type 2 diabetes reported low levels of desire, avoided opportunities for sex and wanted intercourse less frequently than women in the control group.

Sexual arousal is difficult to evaluate due to its complexity (7). Women tend to rate their subjective arousal on their mental excitement, rather than on an appreciation of genital changes (8). Few studies focus intently on subjective arousal. The potential contributory factor of low estrogen levels is not identified in the study by Schreiner-Engel et al (20), which found that $29 \%$ of women with type 2 diabetes reported minimal lubrication, and almost one-half of the women always used a supplementary lubricant, whereas only $13 \%$ of women in the control group did so. Twenty women with diabetes studied by LeMone (24) "frequently reported changed lubrication", but their estrogen status was not clarified. Thus, the statement in Enzlin et al's recent review (25) that "a reduction (in sexual arousal) has been confirmed in most studies" must be viewed cautiously given that the reduction in question may have referred to genital congestion and lubrication, and may have been a result of the women's estrogen status.

Tyrer et al (26) found that women with symptomatic autonomic neuropathy and objectively impaired autonomic cardiovascular reflexes reported decreased nongenital physiological markers of arousal, but reported subjective genital lubrication similar to that of women in the control group. Vaginal plethysmograph measurement showed reduced vasocongestion in seven women with type 1 diabetes who viewed erotic material compared with the control group (27). Interestingly, subjective arousal was similar to that of the women in the control group. Reduced autonomic neurotransmission most likely impairs genital response but may not be of clinical importance.

A literature review suggests that problems with orgasm are not more common in men or in women who have diabetes. Hulter et al (21) suggested that increased numbers of women with type 1 diabetes had orgasmic difficulties. However, only four of 42 women studied did so. The fact that orgasmic experiences may be possible without a partner or without certain sexual practices has not been investigated.

The question of whether sexual dysfunction is associated with complications of diabetes has been addressed either by asking questions about the presence of somatic and/or autonomic neuropathy symptoms, by the measurement of somatic nerve function (vibration threshold, limb reflexes) or by the measurement of autonomic cardiovascular reflexes (26). Some authors have noted the presence of retinopathy or neuropathy. No definite correlation has been found between sexual dysfunction and the complications of diabetes $(19,28-32)$. The following studies purport to have found some level of association.

- Tyrer et al (26) showed reduced nongenital arousal but not reduced subjective genital arousal in women with complicated type 1 diabetes.

- Leedom et al (33) studied women with type 1 and type 2 diabetes, and reported that those with demonstrable neuropathy complained of reduced lubrication, orgasmic difficulties and low desire. However, these women also scored high on depression inventories.

- In a sample of 80 women with type 1 diabetes, more patients reported sexual dysfunction if they also had peripheral neuropathy (29). However, 
the women did not differ from a control group in terms of the number who reported sexual dysfunction (25\% in both groups), and estrogen status was not given.

- By studying peripheral nerve damage using vibration thresholds and limb reflexes, and by taking a history of autonomic or somatic neuropathy, Hulter et al (21) found that of 42 women with type 1 diabetes, only two symptoms of autonomic neuropathy (decreased foot perspiration and increased gustatory sweating) correlated with sexual dysfunction. However, the incidence of sexual dysfunction was comparable with that in large community samples (34).

Unfortunately, two groups of women have not been studied: those who are more medically unwell and those unwilling to address their (possibly very problematic) sexuality at all.

In summary, knowing that the neuropathy of diabetes has a predilection for autonomic nerves and acknowledging the vascular pathology of diabetes, the expected direct effect on a woman's sex response cycle is a reduction in lubrication and in the congestion of erectile tissue. However, women may have a built-in reserve mechanism such that the reduced lubrication and vasocongestion may not necessarily be symptomatic. The woman with diabetes and an estrogen deficiency may be symptomatic. The reduced production of NO from endothelial cells that are associated with her diabetes (3) compounds the effect of the reduced availability of NO due to a lack of estrogen (35).

\section{RESEARCH DESIGN AND METHODS}

Based on past research and clinical observations, the present study was designed to test the following hypotheses that women with diabetes:

- do not have clinically relevant reduced lubrication, if a low estrogen state is excluded;

- do not report more orgasmic difficulties whether the stimulation is masturbation, manual, oral or intercourse;

- do have more dyspareunia based on their predilection for recurrent urinary tract infections, vaginal infections and, possibly, vulvar vestibulitis syndrome;

- have similar sexual desires in terms of sexual fantasies, sexual thoughts and an urge to selfstimulate;

- may agree that their sexuality is affected by pain from neuropathy, fatigue, the perception of the self as being ill, finding and keeping a partner, becoming dependent on a partner, hypoglycemia that is associated with sexual activity, negative body image due to physical changes that are associated with diabetes, and diabetes-associated birth control and reproductive concerns;

- have somewhat lower overall sexual satisfaction, especially women with type 2 diabetes; and

- are not more likely to have sexual dysfunction if the diabetes results in complications.

An extensive questionnaire was developed to assess the sexual response cycle and sexual desire in traditional ways by using questions from previously validated questionnaires $(36,37)$, plus questions that addressed details on orgasmic releases of arousal. Further questions addressed the effects of diabetes on other aspects of women's sexuality. The questionnaire was then modified to be appropriate for women in the control group. Asking 10 women from each group to complete the surveys twice at six-week intervals indicated that the questionnaire had a sufficient level of test-retest reliability. The surveys were then pilot-tested on 20 women with and 20 women without diabetes, and expanded to include more questions on living with diabetes. Participants completed the surveys at home and anonymously mailed them back to the researchers. The study was approved by the University of British Columbia and Vancouver Hospital Ethics Committees, Vancouver, British Columbia. The pilot study was approved by Lions Gate Hospital, Vancouver.

Participants were asked about their medical status and history, including current medications, menopausal status, hormone replacement therapy (HRT), number of pregnancies and number of children. Both groups were then asked sets of questions pertaining to relationship quality, sexual satisfaction, sexual frustration, sexual desire, vaginal lubrication, frequency of yeast infection, dyspareunia, sexual behaviours, and patterns of arousal and orgasm. The women with diabetes were also asked about insulin use, age of diagnosis and complications of diabetes (neuropathy, retinopathy, nephropathy); they were asked to report on each of the following items (by checking the appropriate category "Not at all true of me", "Somewhat true of me" or "Very true of me").

- Pain from neuropathy is distracting when I am sexual or lessens my sexual desire.

- Fatigue from diabetes lessens my sexual desire.

- Thinking that I am an 'ill' woman lessens my sexual feelings.

- Finding or keeping a sexual parter is difficult for me - I worry that they may consider me an 'ill' person. 
- I worry that I may become dependent on a sexual partner because of diabetic complications.

- I become hypoglycemic with sexual activity and preventing this is a concern for me.

- I have a poor body image due to physical changes from diabetes.

- Inability to find a birth control method that is okay with my diabetes causes me to avoid sex.

- Reproductive concerns related to diabetes (eg, fertility, pregnancy, baby's health) have lessened my sexual feelings.

To determine the mood of a participant, five questions addressing the following issues were taken from the Beck Depression Inventory: sadness, satisfaction, hopelessness, interest in activities and interest in people. An example of the response scale for sadness is from 0 ("I do not feel

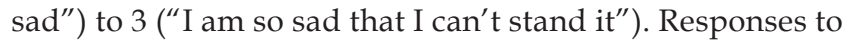
the five questions from the Beck Depression Inventory attained a sufficient level of interitem reliability, alpha = 0.93 , to be aggregated into a single variable labelled 'mood'.

Sexual desire was assessed by using traditional questions about the frequency of sexual thoughts or fantasies, planning something sexual, wanting to be sexually active with a partner and wishing to self-stimulate. Further questions addressed topics such as the following:

- describing subjective arousal and orgasm patterns by choosing one of four graphs that best described experiences with intercourse, partner stimulation other than intercourse and self-stimulation. The first graph depicted arousal, plateau and one peak of orgasmic release as in the traditional concept of the male sexual response. The second graph depicted arousal to a satisfying level with resolution as the stimulation ceased with subsequent satisfaction (but there was no definite peak of arousal with release, ie, orgasm). The third graph depicted a flattened response without satisfaction and the fourth graph depicted a satisfactory response with multiple orgasmic releases;

- how often a woman experienced difficulty becoming sufficiently wet or lubricated in the vagina when she wanted to be sexually intimate; and

- the frequency of pain or discomfort with intercourse.

\section{TABLE 1}

Demographic data for three groups: women with type 1 diabetes, women with type 2 diabetes and women without diabetes

\begin{tabular}{lccc}
\hline & \multicolumn{3}{c}{ Participant group } \\
& $\begin{array}{c}\text { Type 1 } \\
\text { diabetes }\end{array}$ & $\begin{array}{c}\text { Type 2 } \\
\text { diabetes }\end{array}$ & Control \\
\hline Age range in years & 20 to 76 & 31 to 87 & 19 to 68 \\
Mean age in years & 40.18 & 51.96 & 38.96 \\
Completed high school* & 75.80 & 72.70 & 98.50 \\
High school graduates going & & & \\
$\quad$ to university or college* & 87.00 & 75.00 & 92.50 \\
Mean number of pregnancies & 1.49 & 3.10 & 1.47 \\
Mean number of children born & 0.95 & 2.10 & 0.82 \\
Postmenopausal* & 19.10 & 44.40 & 17.90 \\
ERT if postmenopausal* & 43.00 & 33.00 & 58.00 \\
European or Caucasian* & 66.70 & 56.40 & 86.80 \\
Asian* & 10.20 & 0.00 & 8.80 \\
First Nations* & 4.50 & 10.80 & 1.50 \\
Other ethnic origins & & & \\
$\quad$ (or no response)* & 18.60 & 32.80 & 2.90 \\
\hline
\end{tabular}

*Percentage of participants within each group. ERT Estrogen replacement therapy

Questionnaires were distributed to women attending two hospital-based diabetes clinics and to women visiting their family physicians for nonacute, nonsexual concerns in eight separate offices in the Vancouver area. To minimize the likelihood of confounding factors produced by the presence of certain medical conditions thought to potentially interfere with sexuality, the women were asked to read a list of medical conditions and to indicate if any of the conditions were present. If so, they were asked to return their questionnaires uncompleted.

Two hundred fifty questionnaires for each group (women with diabetes and women without diabetes) were distributed to the clinics and offices. Either the physician or a nurse introduced the question of voluntary participation in the study. It proved impossible to calculate the response rate accurately because not all of the offices were sure that only women who intended to complete a questionnaire were given one. Also, rather than checking off any coincidental medical condition that was most likely to affect sexuality and mailing the questionnaire back, women apparently simply discarded the questionnaires. It is estimated that the response rate was between $50 \%$ and $65 \%$.

\section{Participants}

\section{RESULTS}

Table 1 shows a comparison of the demographic characteristics of the three groups of participants (36 women with type 1 diabetes, 27 with type 2 diabetes and 67 without diabetes). Table 2 shows the reported sexual activity and orientation of the participants in each group. 
TABLE 2

Sexual orientation and activity for three groups: women with type 1 diabetes, women with type 2 diabetes and women without diabetes

\begin{tabular}{|c|c|c|c|}
\hline \multirow[b]{2}{*}{ Sexual orientation and activity } & \multicolumn{3}{|c|}{ Participant group } \\
\hline & $\begin{array}{c}\text { Type } 1 \\
\text { diabetes }\end{array}$ & $\begin{array}{c}\text { Type } 2 \\
\text { diabetes }\end{array}$ & Control \\
\hline \multicolumn{4}{|l|}{ Currently sexually active } \\
\hline with a partner & 62.20 & 50.00 & 70.60 \\
\hline \multicolumn{4}{|l|}{ Sexually active in the past } \\
\hline but no current partner & 16.20 & 27.30 & 19.10 \\
\hline \multicolumn{4}{|l|}{ Have a sexual partner but am not } \\
\hline \multicolumn{4}{|l|}{ No partner and have never been } \\
\hline sexually active & 5.40 & 0.00 & 1.50 \\
\hline Heterosexual & 86.50 & 81.80 & 85.30 \\
\hline Gay/Lesbian & 0.00 & 9.10 & 11.80 \\
\hline Bisexual & 5.40 & 0.00 & 2.90 \\
\hline
\end{tabular}

Figures represent percentages within each group

\section{Group differences}

Three-group (type 1 diabetics versus type 2 diabetics versus the control group) ANOVAs were conducted on participants' ages, levels of depression and perceptions of interpersonal relationships. These analyses yielded a group effect for the age of the participants, $\mathrm{F}(3,122)=11.80, \mathrm{P}<0.001$. Turkey's post hoc comparisons revealed that women with type 2 diabetes were significantly older (mean $[\mathrm{M}]=50.36$ ) than women with type 1 diabetes $(M=38.19)$ and control participants $(\mathrm{M}=38.96)$. The group effects for levels of depression, $\mathrm{F}(2,124)=1.09$, and perceptions of interpersonal relationships, $F(2,99)=1.49$, were not statistically significant. On average, participants in all groups had positive perceptions of their intimate relationships (scores were between 3.00 and 3.50 on scales from 1 [low] to 4 [high] on perceptions of relationship quality) and reported relatively low levels of depression (scores were between 0 and 0.55 on scales from 0 [low] to 3 [high] on depressed mood). Given the age differences among participants in the three groups, age was controlled for, where possible, in all subsequent analyses.
A group ANCOVA, controlling for age, on the frequency of yeast infections yielded a main group effect of $\mathrm{F}(2,118)=8.88, \mathrm{P}<0.01$. Age was also a significant covariate, $\mathrm{F}(1,119)=4.50, \mathrm{P}<0.05$. Participants with type 2 diabetes $(\mathrm{M}=3.28)$ reported more yeast infections than the control group ( $\mathrm{M}=1.89)$. Older participants were less likely to experience yeast infections than younger participants, $\mathrm{r}(123)=-0.05$.

Three $\chi^{2}$ analyses on the extent to which women with type 1 diabetes versus women with type 2 diabetes reported complications as a result of their diabetes (nephropathy, neuropathy and retinopathy), yielded group differences on the effect of diabetes on kidneys, $\chi^{2}(1)=8.04, P<0.01$, and retinas, $\chi^{2}(1)=5.54, P<0.05$, but not on nerves, $\chi^{2}(1)=1.44$. Type 1 diabetes was associated with more complications (nephropathy [29.7\%], retinopathy [43.2\%] and neuropathy [37.8\%]) than type 2 diabetes (nephropathy [0\%], retinopathy [13.6\%] and neuropathy [22.7\%]).

\section{Outcomes of hypotheses}

Hypothesis 1: A one-way (group) ANCOVA, controlling for age, yielded no differences in lubrication, $F(2,84)=0.97$. There was also no effect for age, $F(1,84)=1.45$. Although group differences were not observed in the frequency of reduced lubrication $(40.4 \%$, $47.35 \%$ and $34.6 \%$, respectively for women with type 1 diabetes, women with type 2 diabetes and women without diabetes), it is interesting to note that of the seven postmenopausal women with type 1 diabetes, only three used estrogen, and of the 12 postmenopausal women with type 2 diabetes, only four used estrogen, whereas for the 12 postmenopausal women without diabetes, seven used estrogen.

Hypothesis 2: A $\chi^{2}$ analysis yielded no differences in the extent to which participants experienced orgasm with intercourse $\chi^{2}(2)=1.39$, with manual stimulation $\chi^{2}(2)=2.29$ or while masturbating $\chi^{2}(2)=1.44$ (Table 3 ). In addition, there were no group differences in the experience of either one peak or multiple peaks of sexual tension and subsequent release. However, the following interesting findings did emerge (Table 3).

\section{TABLE 3}

Group means and F-scores on dependent measures of sexual functioning and sexual satisfaction

\begin{tabular}{|c|c|c|c|c|}
\hline \multirow[b]{2}{*}{ Dependent measure } & \multicolumn{3}{|c|}{ Group } & \multirow[b]{2}{*}{$\mathbf{F}$} \\
\hline & $\begin{array}{l}\text { Women with } \\
\text { type } 1 \text { diabetes }\end{array}$ & $\begin{array}{c}\text { Women with } \\
\text { type } 2 \text { diabetes }\end{array}$ & Control & \\
\hline Difficulty with vaginal lubrication* & 40.18 & 46.95 & 34.04 & 0.97 \\
\hline Pain during intercourse* & 31.48 & 41.95 & 26.12 & 0.98 \\
\hline Sexual frustration during self-stimulation* & 13.12 & 7.47 & 10.49 & 0.24 \\
\hline Sexual frustration during oral stimulation* & 16.26 & 32.07 & 24.82 & 1.05 \\
\hline Sexual frustration during intercourse* & 37.64 & 31.32 & 33.29 & 0.20 \\
\hline Satisfaction with sexual activity other than intercourse ${ }^{\dagger}$ & 3.28 & 3.14 & 3.45 & 0.75 \\
\hline
\end{tabular}

*Percentage of participants within each group; ${ }^{\dagger}$ level of satisfaction from 1 (extremely dissatisfied) to 4 (very satisfied) 
- The classic (male pattern) 'mountain' or single peak orgasm (pattern 1) was, indeed, the most common pattern of the masturbatory experience for all three groups. Fewer women with type 2 diabetes (39\%) reported pattern 1 from oral or manual stimulation. Intercourse was only associated with a single peak orgasm approximately half as often $(33 \%$ and $35 \%$ of the time, respectively, in women with type 1 diabetes and in the control group, and $15 \%$ of the time in women with type 2 diabetes).

- Fairly similar percentages of all three groups experienced multiple orgasms (pattern 4) both with intercourse and manual or oral stimulation, and less often with self-stimulation.

- A plateau of arousal without a definite peak in release (pattern 2) was experienced with intercourse by approximately one-quarter of the women with type 1 diabetes and by approximately one-third of the women without diabetes; however, it was rarely experienced with self-stimulation, manual or oral stimulation by women in any group.

- A fairly low curve with minimal arousal (pattern 3) was extremely rare with self-stimulation, or oral or manual stimulation in any woman; however, it was experienced during intercourse by $6.1 \%, 15 \%$ and $9.7 \%$ of women with type 1 diabetes, women with type 2 diabetes and women without diabetes, respectively.

- Few women in any group experienced sexual frustration with self-stimulation.

Hypothesis 3: Pain with intercourse was present in $31.48 \%$ of women with type 1 diabetes, $41.95 \%$ of women with type 2 diabetes and $26.12 \%$ of women without diabetes. Of note is the high number of women from all groups who reported experiencing pain (Table 3). However, a one-way (group) ANCOVA, controlling for age, yielded no group differences in the frequency of pain experienced, $F(2,21)=0.98$.

Hypothesis 4: Sexual desire was similar across groups. Three one-way (group) ANCOVAs, controlling for age, yielded no group differences on three of the dependent variables regarding sexual desire (sexual thoughts, $F[2,122]=0.62$; sexual planning, $F[2,122]=1.26$; and desire for sex with a partner, $F[2,122]=0.60)$. Age was a significant covariate of sexual thoughts, $\mathrm{F}(1,1.22)=25.04$, $\mathrm{P}<0.001$; sexual planning, $\mathrm{F}(1,122)=9.99, \mathrm{P}<0.01$; desire for sex with a partner, $\mathrm{F}(1,122)=30.64, \mathrm{P}<0.001$; and desire for self-stimulation, $\mathrm{F}(1,122)=7.79, \mathrm{P}<0.01$. In all cases, sexual desire was greater in younger than in older women (intercorrelations between age and sexual thoughts were $r[126]=-0.45, \mathrm{P}<0.001$; sexual planning, $r[126]=-0.32, \mathrm{P}<0.01$; desire for sex with a partner, $\mathrm{r}[126]=-0.45, \quad \mathrm{P}<0.001 ; \quad$ desire for self-stimulation, $\mathrm{r}[126]=-0.23, \mathrm{P}<0.05)$.

Hypothesis 5: Aspects of diabetes that were perceived to affect sexuality included fatigue and the fear of becoming dependent on a partner. These factors were "somewhat or very true for me" for $51.40 \%$ of women with type 1 diabetes and $36.40 \%$ of women with type 2 diabetes, and $29.70 \%$ and $27.30 \%$ of these groups, respectively, thought they had a poor body image due to physical changes from diabetes.

A series of $\chi^{2}$ analyses compared whether women with type 1 and type 2 diabetes scored differently on any of the questions about living with diabetes. The only difference was on the question related to hypoglycemia; more women with type 1 diabetes (39.70\%) were concerned with becoming hypoglycemic during sexual activity than those with type 2 diabetes $(4.5 \%), \chi^{2}(1)=6.06, P<0.02$.

Hypothesis 6: No group differences were observed on sexual satisfaction. In general, participants across the groups reported feeling relatively satisfied with their sexual relationships. Mean scores for all groups were between 3 (satisfied in most respects) and 4 (very satisfied).

Hypothesis 7: Actual sexual dysfunction was not associated with evidence of diabetic complications. However, there was some association between the fear of feeling dependent and the presence of retinopathy, $\mathrm{r}(56)=0.30, \mathrm{P}<0.05$ or nephropathy, $\mathrm{r}(56)=0.45, \mathrm{P}<0.001$.

\section{DISCUSSION}

The present study provided confirmation that the neurological and vascular pathophysiology of diabetes does not directly interfere with the sexual response of women with diabetes in ways that are clinically relevant. We had postulated (hypothesis 1) that the mechanism of genital congestion and lubrication has some reserve mechanism such that if estrogen were not lacking, diabetes-associated impairment of the mechanism of genital arousal would not be symptomatic. We had suspected that the few studies that reported reduced lubrication reflected an undisclosed lack of estrogen. This study, interestingly, confirms our own clinical experience that uncertainty about cardiovascular benefit from HRT in women who may already have a degree of coronary artery disease (38) causes many women not to take it.

Previous studies did not allow for variation in the orgasmic responses of women. Our experience is that although many women do not experience the typical 'male' single peak of excitement and release, they are entirely functional. By allowing women to choose from a number of possible arousal and orgasm patterns, we demonstrated the diversity of arousal responses. We also demonstrated similar arousal experiences for women with diabetes of either type and without diabetes. Although the 'male pattern' (the pattern 1 response) was commonly associated with masturbation and with direct genital stimulation by a partner, it was experienced during intercourse far less often by all women (eg, only 
$15 \%$ of women with type 2 diabetes reported a pattern 1 response with intercourse, but $58 \%$ reported such a response with self-stimulation). Multiple orgasms (the series of peaks in pattern 4) were not uncommon and occurred more commonly with partner sex than with masturbation. The need to enquire about orgasmic response to nonintercourse stimulation is demonstrated by the finding that the minimal response (pattern 3) was extremely rare in women with selfstimulation or direct genital stimulation by a partner, but was experienced $6.1 \%$ to $15 \%$ of the time during intercourse.

Of the women with type 1 diabetes, $31.5 \%$ reported pain during intercourse, as did $42 \%$ of women with type 2 diabetes and $26.1 \%$ of women without diabetes. Although there were no group differences, these findings are very relevant clinically. If more than $25 \%$ of women in a nonclinical sample (ie, not presenting in a sexual medicine setting) have dyspareunia (and if about $42 \%$ of women have dyspareunia if type 2 diabetes is present), this issue must surely be addressed. It should be noted that younger women in a large American community national health and life study reported a $20 \%$ prevalence of dyspareunia (3). Sadly, usually only the 'biological' components of dyspareunia, most likely a biopsychosexual entity, are addressed. When no biological etiology is discovered, the assessment ends. Not all women with dyspareunia have physical findings that can be documented currently (39). Thus, for some women, dyspareunia represents a pain syndrome (with possible sexual repercussions), whereas for other women, often unexplored psychological issues cause the entry or attempted entry of the penis to be painful. This group of women may have higher rates of psychological symptomatology (39). It is possible that the highest result in the present study (in the women with type 2 diabetes) stems from the infrequency of HRT use and the higher number of yeast infections reported by this group. Genital lack of estrogen and recurrent yeast infection, however, are highly treatable (without invoking systemic estrogen replacement therapy). Long term hypersensitivity and inflammation of the introital edge and entry dyspareunia (the classic symptoms of vestibulitis) can follow recurrent candidiasis $(22,23)$, providing another possible way in which diabetes predisposes women to dyspareunia.

Given the vast number of biopsychosocial determinants of desire, any effect of diabetes on desire would have to be dramatic to cause a statistically significant change. Clearly, there is no theoretical rationale for an obvious direct biological factor - diabetes does not affect the hormonal basis of desire.

Our study demonstrated some diabetes-associated factors that affect women's sexuality (hypothesis 5): fatigue and the fear of becoming dependent on a partner were "somewhat or very true of me" for $50 \%$ of women with type 1 diabetes and $36 \%$ of women with type 2 diabetes. Thirty-two per cent of women with type 1 diabetes and $29 \%$ of women with type 2 diabetes believed that their body image suffered due to physical changes from diabetes. It was interesting to note how infrequently women with diabetes perceived their sexuality to be affected by diabetes-associated difficulties with birth control, with finding a partner or with the perception of 'being an ill woman'.

A reduction in overall sexual satisfaction in the women with type 2 diabetes was not confirmed (hypothesis 6). This finding had been reported by Schreiner-Engel et al (20), who noted the likelihood of having difficulties adapting to the disruptive effects of being ill during an established relationship at a time when many other changes are occurring. Earlier studies had commented on a possible "cultivation of a sick role" (40) by some women with late onset diabetes, with a resulting negative impact on their sexuality (41). A larger study than either the Schreiner-Engel et al study (20) or the present one, with strict age-matching against controls, may clarify this issue further.

We had not expected any correlation between actual sexual dysfunction and diabetic complications (hypothesis 7), and none was found. However, there was a correlation between the fear of becoming dependent and the presence of diabetic complications of retinopathy or nephropathy.

\section{CONCLUSIONS}

The present study investigated the sexuality of women with and without diabetes from a biopsychosocial perspective. Many aspects of sexuality were found to be very similar in women with both types of diabetes and in women without diabetes. The study included women who were currently sexually active, those who were only sexually active in the past and some women who had never been sexually active with a partner. Thus, women who may have had sexual dysfunctions that precluded relationships would not have been excluded from this study. Nevertheless, there was no statistically significant increased incidence of sexual dysfunction in women with diabetes. Dyspareunia, however, was confirmed to be present in more than $40 \%$ of women with type 2 diabetes (Table 3). This finding may be at least partially explained by the lower incidence of estrogen replacement therapy and the higher frequency of yeast infections reported by this group of women. The finding that more than $25 \%$ of women without diabetes who consult a family practitioner for nonsexual concerns have dyspareunia promotes continued research into more effective management of this distressing condition. This study also briefly examined how other aspects of a chronic illness, such as diabetes, may affect sexuality; fatigue, the fear of becoming dependent on a partner and changes in body image due to the illness were found to be relevant. In keeping with previous research, no direct correlations between diabetic complications and actual sexual dysfunctions were found.

Limitations of the study include the modest sample size and the inability to document the response rate precisely. The women's identifying graphs, representing their subjective sexual arousal and any orgasmic release, showed no group differences. However, directly questioning both subjective arousal and sexual pleasure from direct genital stimulation (in addition to awareness of lubrication), may provide further indirect assessment of sexually relevant genital vasocongestion (7). The women with type 2 diabetes 
were older (reflective of the population at risk for type 2 diabetes) and, thus, there was concern that any increased incidence in dysfunction would be a reflection of age or associated postmenopausal state. However, the group with type 2 diabetes was not shown to be statistically significantly more dysfunctional or dissatisfied; thus, the lack of age-matching is less pertinent. A major limitation of this and any similar study is that women who are uncomfortable with addressing sexuality are unlikely to be assessed given the entirely voluntary nature of such research.

ACKNOWLEDGEMENTS: Research was supported by Grant FCA-CON-97-003 from Pfizer Canada Inc, to the first author and, for the pilot study, from Lions Gate Hospital Research Foundation. The assistance of Drs Peter Rees and Lance Rucker for the review of the manuscript and of Mrs Maureen Piper for secretarial assistance is gratefully acknowledged. We also thank the physicians at the Vancouver Hospital, St Paul's Hospital, and Lions Gate Hospital diabetic clinics and the UBC Family Practice Unit and the Family Physicians' offices who distributed the questionnaires.

\section{REFERENCES}

1. Tiefer L. Historical, scientific, clinical and feminist criticisms of "the human sexual response cycle" model. Annu Rev Sex Res 1991;11:1-24.

2. Baumeister RF, Catanese KR, Vohs KD. Is there a gender difference in strength of sex drive? Theoretical views, conceptual distinctions, and a review of relevant evidence. Pers Soc Psychol Rev 2001. (In press)

3. Hoffman D, Seftel AD, Hampel N, Resnick MI. Advanced glycation end-products quench cavernosal nitric oxide. J Urol 1995;153:441A. (Abst)

4. Buvat J, Buvat-Herbaut M, Lemaire A, Marcolin G, Quittelier E. Recent developments in the clinical assessment and diagnosis of erectile dysfunction. Annu Rev Sex Res 1990;1:265-308.

5. Report of the International Consensus Development Conference on female sexual dysfunction: definitions and classifications. The consensus panel on definition and classification of female sexual dysfunction. J Urol Mar 2000;163:888-93.

6. Regan P, Berscheid E. Belief about the state, goals and object of sexual desire. J Sex Marital Ther 1996;22:110-20.

7. Basson R. The female sex response - A different model. J Sex Marital Ther 2000;26:51-65.

8. Laan E, Everaerd W, van der Velde J, Geer JH. Determinants of subjective experience of sexual arousal in women: Feedback from genital arousal and erotic stimulus content. Psychophysiology 1995;32:444-51.

9. Everaerd W, Laan E, Both S, van der Velde J. Female sexuality. In: Szuchman LT, Musarella F, eds. Psychological Perspectives of Human Sexuality. New York: John Wiley and Sons Inc, 2000.

10. Levin RJ. The mechanics of human female sexual arousal. Annu Rev Sex Res 1992;3:1-48.

11. Palle C, Bredkjaer HE, Fahrenkrug J, Ottesen B. Vasointestinal polypeptide loses its ability to increase vaginal bloodflow after menopause. Am J Obstet Gynecol 1991;164:556.

12. Park K, Goldstein I, Andry C, Siroky MB, Krane RJ, Azadzoi KM. Vasculogenic female sexual dysfunction. The hemodynamic basis for vaginal engorgement insufficiency and clitoral erectile insufficiency. Int J Impot Res 1997;97:27-37.

13. Burnett AI, Calvin DC, Silver RI, Pepas DS, Docimo SG. Immunohistochemical description of nitric oxide synthase isoforms in human clitoris. J Urol 1997;158:75-8.

14. Thomas AM, LoPiccolo J. Sexual functioning in persons with diabetes. Issues in research, treatment, and education. Clin Psychol Rev 1994;14:61-86.

15. Laan E, Everaerd W. Determinants of female sexual arousal: Psycho-physiological theory and data. Annu Rev Sex Res 1995;6:32-76.

16. Surridge DH, Erdahl DL, Lawson JS, et al. Psychiatric aspects of diabetes mellitus. Br J Psych 1984;145:269-76.

17. Stancin T, Link DL, Reuter JM. Binge eating and purging in young women IDDM. Diabetes Care 1989;12:601-3.

18. Young EW, Koch PB, Bailey D. Research comparing the dyadic adjustment and sexual functioning concerns of diabetic and non-diabetic women. Health Care for Woman Inst 1989;10:377-94.

19. Newman AS, Bertelson AD. Sexual dysfunction in diabetic woman. J Behav Med 1986;9:261-70.

20. Schreiner-Engel $P$, Schiavi RC, Vietorisz D, Smith H. The differential impact of diabetes type on female sexuality. J Psychosom Res 1987;31:23-33.

21. Hulter B, Berne C, Lundberg PO. Sexual function in women with insulin dependent diabetes mellitus. Scand J Sex 1998;1:43-9.

22. Ashman RB, Ott AK. Auto immunity as a factor in recurrent vaginal candidosis and the minor vestibular gland syndrome. J Reprod Med 1989;34:264-6.

23. Metts JF. Vulvodynia and vulvovestibulitis. Challenges in diagnosis and management. Am Fam Phys 1999;59:1547-56.

24. LeMone P. The physical effects of diabetes on sexuality in women. Diabetes Educ 1996;22:361-6.

25. Enzlin P, Matthieu C, Vanderschueren D, Demyttanaere K. Diabetes mellitus and female sexuality. A review of 25 years' research. Diabetes Med 1998;15:809-15.

26. Tyrer G, Steel J, Ewing D, Bancroft J, Warner P, Clarke BF. Sexual responsiveness in diabetic women. Diabetologia 1983;24:166-71.

27. Wincze JP, Albert A, Bansal S. Sexual arousal in diabetic females: An investigation of physiological and self-report measures. Arch Sex Behav 1993;22:587-600.

28. Kolodny RC. Sexual dysfunction in diabetic females. Diabetes 1971;20:557-9.

29. Jensen SB. Diabetic sexual dysfunction: A comparative study of 160 insulin treated diabetic men and women and an age matched control group. Arch Sex Behav 1981;10:493-504.

30. Ellenberg M. Sexual aspects of the female diabetic. Mt Sinai J Med 1977;4:495-500.

31. Campbell L, Redelman MJ, Borkman RM, McLay JG, Chisholm DJ. Factors in sexual dysfunction in diabetic female volunteer subjects. Med J Aust 1989;151:550-2.

32. Dunning P. Sexuality and women with diabetes. Patient Educ Couns 1973;21:5-14.

33. Leedom L, Feldman M, Procci W, Zeidler A. Symptoms of sexual dysfunction and depression in diabetic women. J Diabet Complications 1991;5:38.41.

34. Laumann EO, Paik A, Rosen RC. Sexual dysfunction in the United States: Prevalence and predictors. JAMA 1999;281:537-44.

35. Caulin-Glaser T, Garci-Cardena G, Sarrel P, Sess WC, Bender JR. Seventeen beta estradiol regulation of human endothelial cell basal nitric oxide release, independent of cytosolic Ca2+ mobilization. Circ Res 1998;1:885-92.

36. Derogatis LR. The Derogatis interview for sexual functioning (DISF/DISF-SR): An introductory report. J Sex Marital Ther 1997;231:290-304.

37. Taylor FJ, Rosen RC, Leiblum SR. Self-report assessment of female sexual functiooning: Psychometric evaluation of the brief index of sexual functioning for women. Arch Sex Behav 1994;23:627-43.

38. Hulley S, Grade D, Buch T, Furberg K, Herrington D, 
Riggs B. Randomized trial of estrogen plus progestin

for secondary prevention of coronary heart disease

in postmenopausal women. Heart and estrogen/progestin

replacement study (HERS) research group. JAMA 1998;280:605-13.

39. Meana M, Binik Y, Khalife S, Cohen D. Biopsychosocial profile of women with dyspareunia. Obstet Gynecol 1997;90:583-9.

40. Piper BA. Women's perceived effect of diabetes mellitus on sexual function and relationship to spouse. J Sex Educ Ther 1982;8:8-21.

41. Dupuis A. Assessment of the psychological factors and responses in self-managed patients. Diabetes Care 1990;3:117-20. 